\title{
Clinical and demographic characteristics of children with familial mediterranean fever in Central Anatolia
}

\author{
Onur Akin ${ }^{*}$, Erkan Demirkaya ${ }^{1}$, Adem Polat $^{1}$, Ezgi Deniz Batu², Yusuf Tunca ${ }^{3}$, Cengizhan Acikel ${ }^{4}$, Harun Peru', \\ Betul Sozeri ${ }^{6}$, Ismail Dursun ${ }^{7}$, Hakan Poyrazoglư ${ }^{8}$, Faysal Gok ${ }^{1}$, Seza Ozen², \\ for the FMF Arthritis Vasculitis and Orphan Disease Research in Paediatric Rheumatology (FAVOR)
}

From 18th Pediatric Rheumatology European Society (PReS) Congress

Bruges, Belgium. 14-18 September 2011

\section{Objective}

This study investigates the clinical and demographic characteristics of Turkish familial Mediterranean fever (FMF) patients and relationship between these characteristics and genotype.

\section{Methods}

115 girls and 143 boys were included in this study. The clinical data of patients were collected from six centers. Genetic analysis was performed using polymerase chain reaction and restriction endonuclease digestion methods to detect the presence of eight FMF gene mutations.

\section{Results}

The mean age of disease onset was $5.1 \pm 3.6$ years and the mean age at diagnosis was $7.3 \pm 3.1$ years. The mean number of attacks per year was $7.7 \pm 7.8$, the mean duration of attacks $1.7 \pm 1.6$ days. The most common clinical manifestations were fever (91.6\%) and abdominal pain $(90.3 \%)$. The other manifestations were arthralgia (44.1\%), arthritis (18.6\%), headache (17.3\%), myalgia (15.6\%), vomiting (11\%), chest pain (6.8\%), splenomegaly (5.5\%), diarrhea (5.5\%) and erisipelas like eritema (3.4\%). Amyloidosis (1.8\%) and proteinuria (1.8\%) were also determined. Most of patients had compound heterozygote genotype $(n=86,28.6 \%)$ and the most common homozygote mutation was M694V homozygosity ( $n=65$, \%21.6). The frequency of headache in the patients with homozygote M694V mutation $(\mathrm{n}=18, \% 29.5)$ and the frequencies of arthritis in patients with homozygote E148Q ( $\mathrm{n}=1, \% 33.3)$ and M694V mutations $(\mathrm{n}=16, \%$ 26.2) were significantly higher than the patients with other mutations $(\mathrm{p}<0.05$, for all of them).

\section{Conclusion}

The results of this study supported the hypothesis that mutation types seem to determine the susceptibility to some clinical features development. With the determination of new mutations, further studies are warranted to investigate relationship between genotype and phenotype in larger populations.

\section{Author details \\ ${ }^{1}$ Gülhane Military Medical Academy, Pediatric Nephrology \& Rheumatology Unit, Ankara, Turkey. ${ }^{2}$ Hacettepe University Medical School, Pediatric Nephrology \& Rheumatology Unit, Ankara, Turkey. ${ }^{3}$ Gulhane Military Medical Faculty, Department of Medical Genetic, Ankara, Turkey. ${ }^{4}$ Gulhane Military Medical Faculty, Department of Public Health, Division of Epidemiology, Ankara, Turkey. ${ }^{5}$ Selcuklu University, Paediatric Nephrology \& Rheumatology Unit, Konya, Turkey. ${ }^{6}$ Ege University Medical School, Pediatric Nephrology \& Rheumatology Unit, İzmir, Turkey. ${ }^{7}$ Kayseri Education and Research Hospital, Kayseri, Turkey. ${ }^{8}$ Erciyes University Medical School, Pediatric Nephrology \& Rheumatology Unit, Kayseri, Turkey.}

Published: 14 September 2011

\section{doi:10.1186/1546-0096-9-S1-P11}

Cite this article as: Akin et al:: Clinical and demographic characteristics of children with familial mediterranean fever in Central Anatolia. Pediatric Rheumatology 2011 9(Suppl 1):P11.

\footnotetext{
* Correspondence: onur3034@hotmail.com

'Gülhane Military Medical Academy, Pediatric Nephrology \& Rheumatology Unit, Ankara, Turkey

Full list of author information is available at the end of the article
}

(c) 2011 Akin et al; licensee BioMed Central Ltd. This is an open access article distributed under the terms of the Creative Commons 